\begin{tabular}{r|l|l|l}
$\begin{array}{c}\text { Case Reports in } \\
\text { Gastroenterology }\end{array}$ & $\begin{array}{l}\text { Case Rep Gastroenterol 2011;5:40-44 } \\
\text { DOl: 10.1159/000323700 }\end{array}$ & $\begin{array}{l}\text { Published online: } \\
\text { January 14, 2011 }\end{array}$ & $\begin{array}{l}\text { O 2011 S. Karger AG, Basel } \\
\text { ISSN 1662-0631 } \\
\text { www.karger.com/crg }\end{array}$ \\
\hline
\end{tabular}

\title{
Survival following Treatment of Aortoesophageal Fistula with Dual Esophageal and Aortic Intervention
}

\author{
Soumitra K. Ghosh ${ }^{\mathrm{a}}$ Farooq Z. Rahman ${ }^{\mathrm{a}}$ Stephen Bown ${ }^{\mathrm{a}, \mathrm{c}}$ \\ Peter Harris $^{\mathrm{b}}$ Kevin Fong ${ }^{\mathrm{d}}$ Louise Langmead ${ }^{\mathrm{a}}$ \\ aDepartment of Gastroenterology, 'bepartment of Vascular Surgery, \\ 'National Medical Laser Centre, and dDepartment of Anaesthetics, \\ University College Hospital, London, UK
}

\section{Key Words}

Esophageal cancer · Aortoesophageal fistula - Gastrointestinal bleed · Esophageal stent

\begin{abstract}
Aortoesophageal fistulas are a rare but commonly fatal complication of esophageal cancer. Reports of successfully managed cases are few, with high mortality and morbidity usually resulting from failure to control the initial massive haemodynamic insult. We report the case of a 47-year-old Caucasian man with recently diagnosed advanced esophageal cancer who suffered an episode of massive haematemesis. Emergency gastroscopy revealed an arterial bleeding point in the proximal esophagus. A self-expanding metal esophageal stent was placed to achieve initial partial haemostasis. $\mathrm{CT}$ angiography confirmed an aortoesophageal fistula. An endoluminal stent device was thus inserted within the thoracic aorta stabilising the bleeding point. The patient subsequently made an uneventful recovery and was discharged on long-term antibiotics for palliative care. He survived for 2 months at home before dying of disseminated malignancy. The successful use of esophageal stenting as a means of achieving haemostasis, allowing time for endovascular intervention, is as yet a relatively unexplored area of management of this rare condition.
\end{abstract}

\section{Introduction}

Aortoesophageal fistula is a rare, devastating and usually fatal condition which has multiple aetiological factors. The first report, in 1818, described the death of a 28 -year-old soldier who exsanguinated after ingesting a beef bone fragment [1]. A comprehensive review, published by Hollander and Quick [2], which included 500 cases of fistula, 


\begin{tabular}{c|l|l|l}
$\begin{array}{r}\text { Case Reports in } \\
\text { Gastruanteriology }\end{array}$ & $\begin{array}{l}\text { Case Rep Gastroenterol 2011;5:40-44 } \\
\text { DOI: 10.1159/000323700 }\end{array}$ & $\begin{array}{l}\text { Published online: } \\
\text { January 14, 2011 }\end{array}$ & $\begin{array}{l}\text { O 2011 S. Karger AG, Basel } \\
\text { ISSN 1662-0631 } \\
\text { www.karger.com/crg }\end{array}$ \\
\hline
\end{tabular}

identified three major causes of aortoesophageal fistula, the main aetiologic factor being aortic disease with $54.2 \%$ of cases secondary to rupture of a descending thoracic aorta aneurysm into the oesophagus. Foreign body ingestion (19.2\%) and advanced esophageal carcinoma (17.0\%) were the next commonest causes.

Regardless of cause, the optimal management of the fistula remains controversial, and recent literature has focused on the role of endovascular techniques and open thoracic surgery [3]. However, high mortality from the condition usually results from massive uncontrolled haemorrhage prior to these interventions being possible. Although non-surgical measures to control the initial haemodynamic insult caused by haemorrhage have been described [3], this remains a relatively unexplored area of management [4].

\section{Case Report}

A 47-year-old Caucasian man with recently diagnosed advanced esophageal cancer attended the imaging department for an ultrasound scan. In the waiting area, the patient had a massive haematemesis and proceeded into a peri-arrest state.

He initially presented two months earlier with progressive dysphagia and weight loss. Significant past medical history included smoking and previous opioid dependence. Gastroscopy revealed a stricturing exophytic mid-esophageal lesion with an apparent fistula. A $12 \times 12$ Hanaro covered stent (M.I. Tech, Seoul, distributed by MTW, Wesel, Germany) was inserted across the lesion. CT confirmed an esophageal tumour in continuity with the right main bronchus with an associated right lung abscess. Despite esophageal stenting the patient developed worsening dysphagia in the following weeks. Repeat gastroscopy identified tumour overgrowth at and over the top of the original stent. An overlapping fully covered $12 \times 18$ Alveolus Aero stent (Alveolus, Charlotte, N.C., USA) was inserted. Despite treatment with intravenous antibiotics, an empyema subsequently developed (fig. 1), presumably because the bronchial fistula had been adequately sealed with the stents, creating an undrained collection in the lung which subsequently fistulated through to the pleural cavity. While awaiting a video-assisted thoracoscopic surgical procedure to drain and seal the abscess and empyema, he spontaneously drained the abscess by coughing up nearly 1 litre of pus in $24 \mathrm{~h}$; this led to a dramatic improvement in his clinical state and resolution of his chest X-ray changes. He was discharged on antibiotics and further staging investigations were scheduled as an outpatient. A week before the ultrasound scan he experienced mid-thoracic pain and small episodes of haematemesis.

When he collapsed, he was tachycardic (heart rate $128 \mathrm{bpm}$ ) with unrecordable blood pressure. Fluid resuscitation was commenced. The patient was anaesthetised and transferred for emergency gastroscopy. This revealed an esophageal lumen full of clotted blood. Its clearance identified a large arterial bleeding point, just above the proximal end of the stent in the mid-esophagus (fig. 2a). A further $28 \mathrm{~mm}$ diameter Niti-S covered esophageal stent (Taewong Medical, Seoul, Korea) was inserted to tamponade the bleeding point (fig. 2b). Despite aggressive resuscitation with fluids and 8 units of blood, there was no improvement in his haemodynamic status until after stent deployment. The patient was transferred to the intensive care unit where fresh bleeding continued to be aspirated from his nasogastric tube overnight. A further 8 units of blood and 6 units of fresh frozen plasma were transfused to maintain his haemoglobin between 7 and $7.7 \mathrm{~g} / \mathrm{dl}$. With this, he remained haemodynamically stable (mean arterial blood pressure 60-80 $\mathrm{mm} \mathrm{Hg}$ ).

CT angiography was performed and demonstrated an aortoesophageal fistula at the level of the carina with ongoing bleeding into the mediastinum (fig. $3 \mathrm{a}$ ). An endoluminal vascular stent (COOK TX2 $36 \mathrm{~mm} \times 120$ ) was inserted into the thoracic aorta distal to the origin of the left subclavian artery sealing the fistula. Repeat CT angiography confirmed haemostasis (fig. 3b). The patient was discharged on long-term antibiotics for palliative care. He survived for 2 months at home, during which he was able to attend to his personal affairs, before dying of disseminated malignancy. 


\begin{tabular}{c|l|l|l}
$\begin{array}{c}\text { Case Reports in } \\
\text { Gastroenterology }\end{array}$ & $\begin{array}{l}\text { Case Rep Gastroenterol 2011;5:40-44 } \\
\text { DOI: 10.1159/000323700 }\end{array}$ & $\begin{array}{l}\text { Published online: } \\
\text { January 14, 2011 }\end{array}$ & $\begin{array}{l}\text { O 2011 S. Karger AG, Basel } \\
\text { ISSN 1662-0631 } \\
\text { www.karger.com/crg }\end{array}$ \\
\hline
\end{tabular}

\section{Discussion}

This case highlights the successful non-surgical management of a massive bleed caused by aortoesophageal fistula. The esophageal stent acted as a means to tamponade and provided partial initial control of the bleeding point. This allowed time for appropriate endovascular intervention in the form of a thoracic endoluminal stent device to further stabilise the haemodynamic status of the patient.

The challenge to recognise and treat successfully before the patient exsanguinates is probably why success stories for closure of aortoesophageal fistulas are few. High clinical suspicion and recognition of warning symptoms such as mid-thoracic pain and sentinel arterial upper gastrointestinal haemorrhage is crucial [5]. Transient self-limiting 'herald' bleeds may precede fatal exsanguination by more than $24 \mathrm{~h} \mathrm{[6].} \mathrm{This} \mathrm{'window} \mathrm{of}$ opportunity' allows early transfer to a specialist centre. High clinical suspicion and recognition of warning symptoms is essential.

Since Parodi et al. first reported using an endoluminal stent graft for repair of abdominal aortic aneurysms [7], thoracic endovascular aortic repair (TEVAR) has become more common in the management of aortoesophageal fistula [3], with much of the literature focusing on endovascular and open surgical management. There is still an ongoing debate as to the appropriate role of these interventions [8]. A recently reported successful surgical approach [9] advocated open transthoracic esophageal resection, cervical esophagectomy and gastrostomy. The patient had developed a fistula secondary to previous TEVAR, so the authors could not decide the best approach to salvage the thoracic aorta. Although successful in stabilising the patient, this highly invasive approach may not be suitable for patients with advanced esophageal malignancy.

Less invasive successful endovascular management of fistulas in patients with esophageal malignancy has been reported. One report [10] describes the use of a Dacron prosthesis interposed into the descending thoracic aorta to restore aortic flow as successful endovascular intervention; the same patient later underwent an esophagectomy for definitive treatment. A separate report [11] describes successful endovascular intervention to stabilise bleeding, although again this patient also went on to require further definitive gastrointestinal surgical management.

Further reports [9-11] appear to suggest that although TEVAR is a useful method for achieving hemodynamic stability, for definitive long-term management the patient will require some form of open surgical intervention. Of course with advanced esophageal malignancy, patients may simply not be suitable for surgery, leaving TEVAR as their only option. The problem with TEVAR remains that it does not prevent immediate exsanguination in patients admitted with fistula. It was found in patients who underwent TEVAR that early esophageal repair appeared to improve survival [12]. Literature on the successful esophageal management of the initial exsanguination remains limited, with the successful use of a Sengstaken-Blakemore tube prior to TEVAR being reported [13]. Newer techniques have been emerging, such as the use of cyanoacrylate embolisation of the fistula followed by TEVAR [14]. The use of esophageal stenting as a means of controlling initial exsanguination remains a relatively unexplored area of management. 


\begin{tabular}{r|l|l|l}
$\begin{array}{c}\text { Case Reports in } \\
\text { Gastroenterology }\end{array}$ & $\begin{array}{l}\text { Case Rep Gastroenterol 2011;5:40-44 } \\
\text { DOI: 10.1159/000323700 }\end{array}$ & $\begin{array}{l}\text { Published online: } \\
\text { January 14, 2011 }\end{array}$ & $\begin{array}{l}\text { O 2011 S. Karger AG, Basel } \\
\text { ISSN 1662-0631 } \\
\text { www.karger.com/crg }\end{array}$ \\
\hline
\end{tabular}

In conclusion, with early recognition, esophageal stenting may have a role in the initial emergency control of bleeding due to aortoesophageal fistula, but clearly, immediate access to anaesthetic, interventional endoscopic and radiological services is mandatory. Further surgical or endovascular intervention would then be essential.

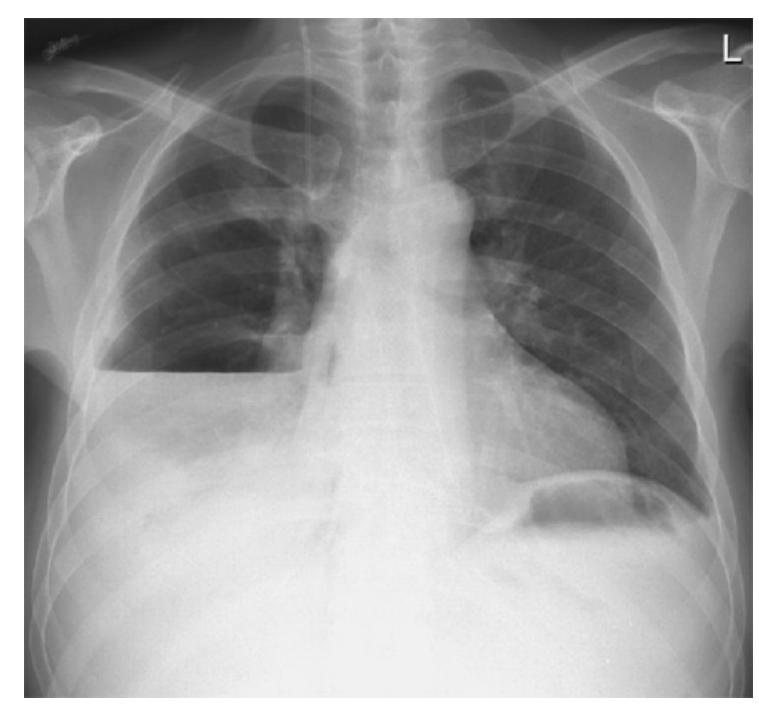

Fig. 1. Chest X-ray showing development of a right-sided empyema in the patient.
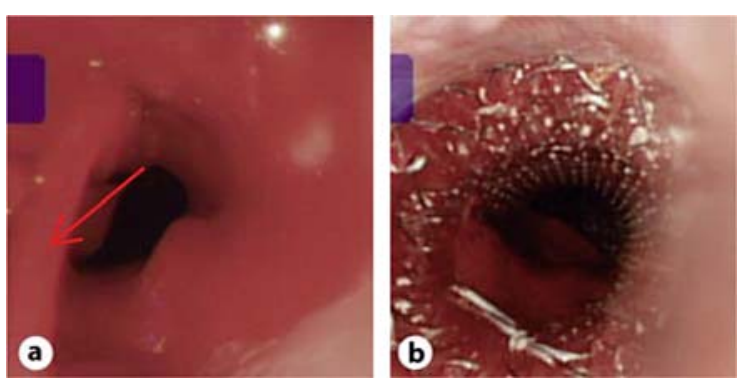

Fig. 2. Endoscopic images. a A large arterial bleeding point (arrow), just above the proximal end of the stent in the mid-esophagus. The jet of blood, which was reckoned to be almost $2 \mathrm{~mm}$ in diameter, goes from the bottom left hand corner to the middle of the top left hand quadrant. b A $28 \mathrm{~mm}$ diameter Niti-S covered esophageal stent (Taewong Medical, Seoul, Korea) was inserted to tamponade the bleeding point. 


\begin{tabular}{r|l|l|l} 
Case Reports in & $\begin{array}{l}\text { Case Rep Gastroenterol 2011;5:40-44 } \\
\text { DOI: 10.1159/000323700 }\end{array}$ & $\begin{array}{l}\text { Published online: } \\
\text { January 14, 2011 }\end{array}$ & $\begin{array}{l}\text { @ 2011 S. Karger AG, Basel } \\
\text { ISSN 1662-0631 } \\
\text { www.karger.com/crg }\end{array}$ \\
\hline
\end{tabular}
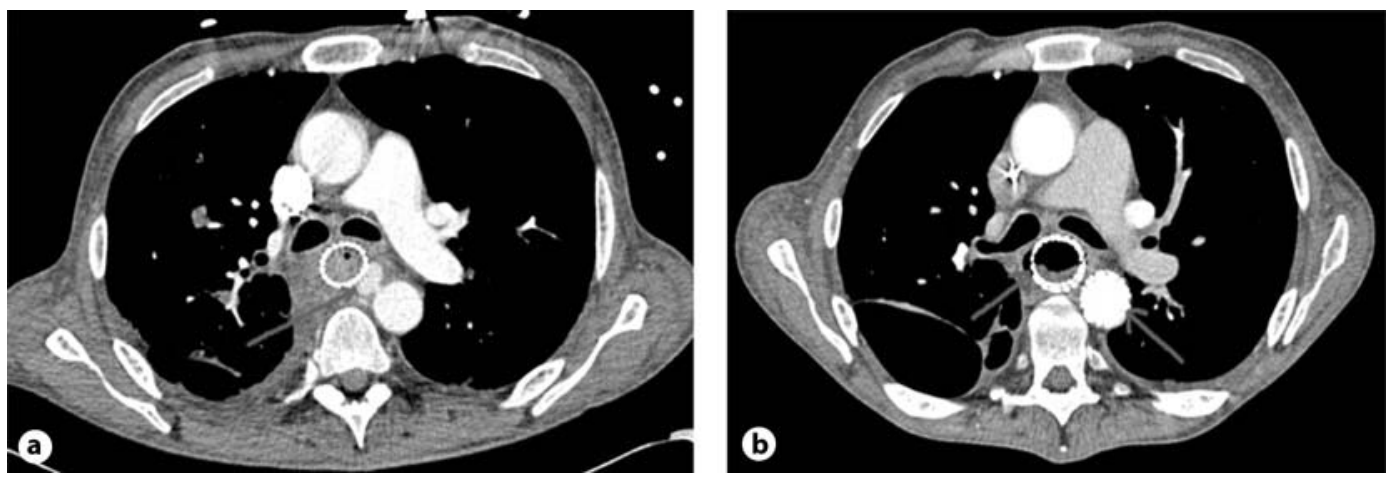

Fig. 3. CT angiography images. a An aortoesophageal fistula at the level of the carina with ongoing bleeding into the mediastinum. The esophagus is filled with old clot without contrast, indicating successful tamponade of the fistula. b An endoluminal vascular stent (COOK TX2 $36 \mathrm{~mm} \times 120$ ) was inserted into the thoracic aorta distal to the origin of the left subclavian artery sealing the fistula. Repeat CT angiography confirmed haemostasis.

\section{References}

1 Dubrueil O: Observation sur la perforation de l'esophague et de l'aorte thoracique par une portion d'os oval: avec des réflexions. J Univ Sci Med 1818;9:357-363.

2 Hollander JE, Quick G: Aortoesophageal fistula: a comprehensive review of the literature. Am J Med 1991;91: 279-287.

3 Flores J, Shiya N, Kunihara T, Yoshimoto K, Yasuda K: Aortoesophageal fistula: alternatives of treatment; case report and literature review. Ann Thorac Cardiovasc Surg 2004;10:241-246.

4 Prokakis C, Charoulis N, Tselikos D, Koletsis EN, Apostolakis E, Dougenis D: Primary aortoesophageal fistula due to thoracic aortic aneurysm: successful surgical treatment. Tex Heart Inst J 2009;36:607-610.

-5 Heckstall RL, Hollander JE: Aortoesophageal fistula: recognition and management in the emergency department. Ann Emerg Med 1998;32:502-505.

6 Carter R, Mulder GA, Snyder EN Jr, Brewer LA 3rd: Aortoesophageal fistula. Am J Surg 1978;136:26-28.

7 Parodi JC, Criado FJ, Barone HD, Schonholz C, Queral LA: Endoluminal aortic aneurysm repair using a balloon-expandable stent-graft device: a progress report. Ann Vasc Surg 1994;8:523-529.

8 Prokakis C, Koletsis E, Apostolakis E, Dedeilias P, Dougenis D: Aortoesophageal fistulas due to thoracic aorta aneurysm: surgical versus endovascular repair. Is there a role for combined aortic management? Med Sci Monit 2008;14:RA48-RA54.

-9 Engelhardt H, Paul A, Niebel W, Dechêne A, Przyborek M, Tsagakis K, Kühl H, Jakob H, Erbel R, Eggebrecht $\mathrm{H}$ : Successful treatment of secondary aortoesophageal fistula after thoracic endovascular aortic repair. Dtsch Med Wochenschr 2010;135:2076-2080.

10 Cairols MA, Izquierdo LM, Barjau E, Iborra E, Romera A: Primary aorto-oesophageal fistula due to oesophageal carcinoma. Report of a successfully managed case. Int Angiol 2000;19:290-293.

11 Ikeda Y, Morita N, Kurihara H, Niimi M, Okinaga K: A primary aortoesophageal fistula due to esophageal carcinoma successfully treated with endoluminal aortic stent grafting. J Thorac Cardiovasc Surg 2006;131: 486-487.

12 Jonker FH, Heijmen R, Trimarchi S, Verhagen HJ, Moll FL, Muhs BE: Acute management of aortobronchial and aortoesophageal fistulas using thoracic endovascular aortic repair. J Vasc Surg 2009;50:999-1004.

$\$ 13$ Kelly SL, Peters P, Ogg MJ, Li A, Smithers BM: Successful management of aortoesophageal fistula caused by fish bone - case report and review of literature. J Cardiothorac Surg 2009;4:21.

14 Ahn M, Shin BS, Park MH: Aortoesophageal fistula secondary to placement of an esophageal stent: emergent treatment with cyanoacrylate and endovascular stent graft. Ann Vasc Surg 2010;24:555.e1-555.e5. 